\title{
Laboratory tests on flow field around bottom vane
}

\author{
M. M. Hossain ${ }^{1}$, Md. Zahidul Islam ${ }^{1}$, Md. Shahidullah ${ }^{1}$, \\ A. de Weerd ${ }^{2}$, P. van Wielink ${ }^{2}$ \& E. Mosselman ${ }^{3}$ \\ ${ }^{I}$ Bangladesh University of Engineering and Technology (BUET), \\ Bangladesh \\ ${ }^{2}$ Avans Hogeschool, The Netherlands \\ ${ }^{3}$ WL/Delft Hydraulics \& Delft University of Technology, \\ The Netherlands
}

\begin{abstract}
Bottom vanes are vortex generating devices that are mounted on the river bed at an angle to the prevailing flow direction. They can be used effectively for sediment management and training of alluvial rivers. We tested the three-dimensional flow field generated by bottom vanes in a $45.6 \mathrm{~m}$ long and $2.45 \mathrm{~m}$ wide straight flume at the open-air physical modelling facility of BUET in Dhaka, Bangladesh, for all combinations of 4 vane heights, 5 vane angles and 2 bed topographies. Both topographies were moulded in concrete. The two bed topographies consisted of a flat bed and a bed with scour holes recorded in preceding mobile-bed experiments. Vanes at an angle of $30^{\circ}$ to the flow were found to generate the strongest vortices. The scour holes did not weaken the vortices appreciably. We conclude therefore that local scour does not jeopardize the effectiveness of bottom vanes.

Keywords: helical flow, vortex, bottom vanes, laboratory experiments.
\end{abstract}

\section{Introduction}

Bottom vanes are vortex generating devices that are mounted on the river bed at an angle to the prevailing flow direction. The pressure difference between the pressure and suction sides of the vanes produces vortices that alter the transverse slope of the alluvial river bed in a zone downstream of the vanes. Thus bottom 
vanes can be used to modify river cross-sections (Potapov \& Pyshkin [1], Remillieux [2], Odgaard \& Kennedy [3] Odgaard \& Spoljaric [4]). This might offer opportunities for low-cost interventions in the numerous rivers of Bangladesh that are responsible for enormous erosion and siltation problems throughout the country every year. An optimal design of bottom vanes for a particular situation requires good insight in the three-dimensional flow generated by the vanes. The three-dimensional flow field around a bottom vane was therefore tested in laboratory experiments for different vane heights as well as different vane angles to the flow. A specific issue was the effect of local scour holes that develop around bottom vanes, because there were some doubts whether those holes would disturb or even eliminate the vane-generated vortex. In the preceding year, the formation of scour holes had been investigated by experiments using a mobile sand bed (Hossain et al. [5]). However, the turbidity resulting from sediment transport hampered measurements of the associated flow field. The present fixed-bed experiments were therefore carried out for both a flat bed and one of the topographies found in the preceding mobile-bed experiments.

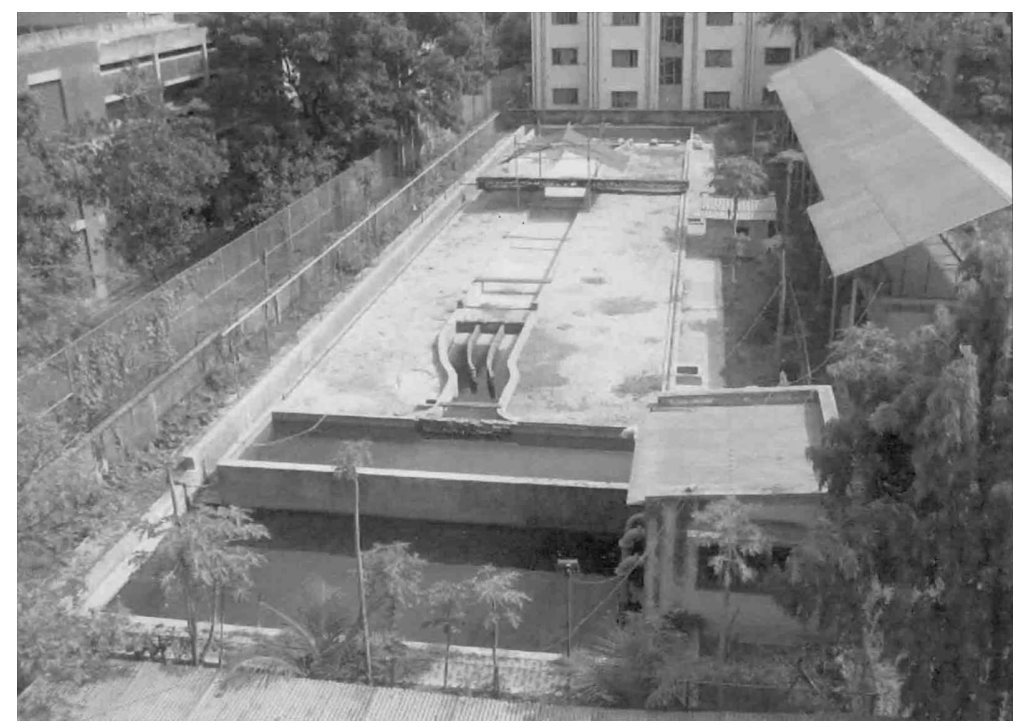

Figure 1: Overview of physical model facility at BUET.

\section{Experimental set-up}

\subsection{Test facility}

The experiments were carried out in a $45.6 \mathrm{~m}$ long and $2.45 \mathrm{~m}$ wide straight flume at the open-air physical modelling facility of BUET in Dhaka, Bangladesh (Figure 1). The flume has a re-circulating water supply system with pre-pump 
storage pool, post-pump upstream reservoir, tailgates, sediment trap and stilling basin. The water discharge could be measured at two sharp-crested Rehbock weirs, one between the upstream reservoir and the flume and one in the recirculation channel. Having established during trial experimentations that no water was lost in the system, only the Rehbock weir in the re-circulation channel was used to measure the discharge on a routine basis at half-hour intervals. Three point gauges along the flume were used to measure water levels and, hence, streamwise water level gradients at one-hour intervals. Flow velocities were measured using a programmable electromagnetic current velocity meter (PEMS), mounted on a movable measurement carriage. The sensor of this instrument determines flow velocity components in two dimensions only, but three-dimensional flow velocity vectors could be obtained by rotating the sensor over $90^{\circ}$ during part of the measurements. P-EMS positions and readings were calibrated daily, as the instrument was removed every evening and re-installed every morning to prevent theft.

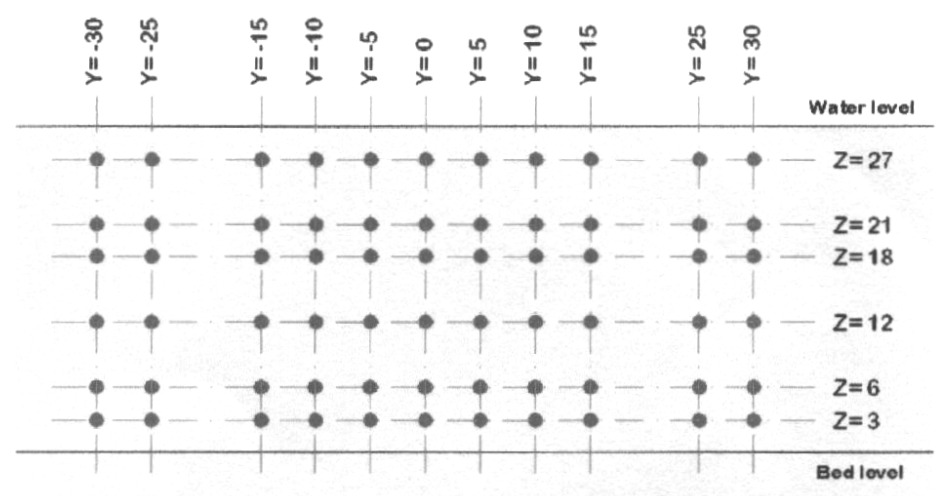

Figure 2: Cross-sectional measurement grid for flow velocity measurements.

\subsection{Co-ordinate system and basic flow and vane parameters}

Streamwise co-ordinates are denoted by $x$, cross-stream co-ordinates by $y$ (positive to the right) and vertical co-ordinates by $z$ (positive upward). The vane was installed at the centre of the flume $(y=0)$ at streamwise co-ordinate $x=15.00 \mathrm{~m}$. Flow velocities were measured in 10 cross-sections at $x=14.00 \mathrm{~m}$, $14.40 \mathrm{~m}, 14.80 \mathrm{~m}, 15.00 \mathrm{~m}, 15.20 \mathrm{~m}, 15.40 \mathrm{~m}, 15.60 \mathrm{~m}, 16.00 \mathrm{~m}, 16.50 \mathrm{~m}$ and $16.90 \mathrm{~m}$. Figure 2 shows the fixed $(y, z)$ locations where for each cross-section the components of the flow velocity vectors were measured. A flow depth of $0.30 \mathrm{~m}$ was maintained in combination with a discharge of $200 \mathrm{l} / \mathrm{s}$. The flume being $2.45 \mathrm{~m}$ wide, these settings implied an average streamwise flow velocity of 
$0.27 \mathrm{~m} / \mathrm{s}$. The vane was made of durable Perspex, $0.40 \mathrm{~m}$ long and $8 \mathrm{~mm}$ thick. Vane heights and vane angles with respect to the flow were varied during the experiments.

\subsection{Construction of scour holes in fixed bed}

Mobile-bed experiments had been carried out during the preceding year to study the effects of bottom vanes on a sand bed topography (Hossain et al. [5]). The resulting topographies had been recorded for 20 test runs with different vane heights and vane angles. The topography resulting from a height of $0.18 \mathrm{~m}$ and an angle of $20^{\circ}$ was moulded in a concrete bed for a detailed study of the corresponding three-dimensional flow field. This topography consisted of two scour holes, one around the vane (A) and one $2 \mathrm{~m}$ downstream (B), as shown in Figure 3. A special mould system was developed for an accurate reproduction of the original topography. An hourglass-shaped area of the fixed concrete bed was kept open for the positioning of the vane in different configurations (Figure 4). For each experimental run, the central part of scour hole A was remoulded in this gap using concrete of a low cement-sand ratio that could be broken away easily to prepare the next experimental run.

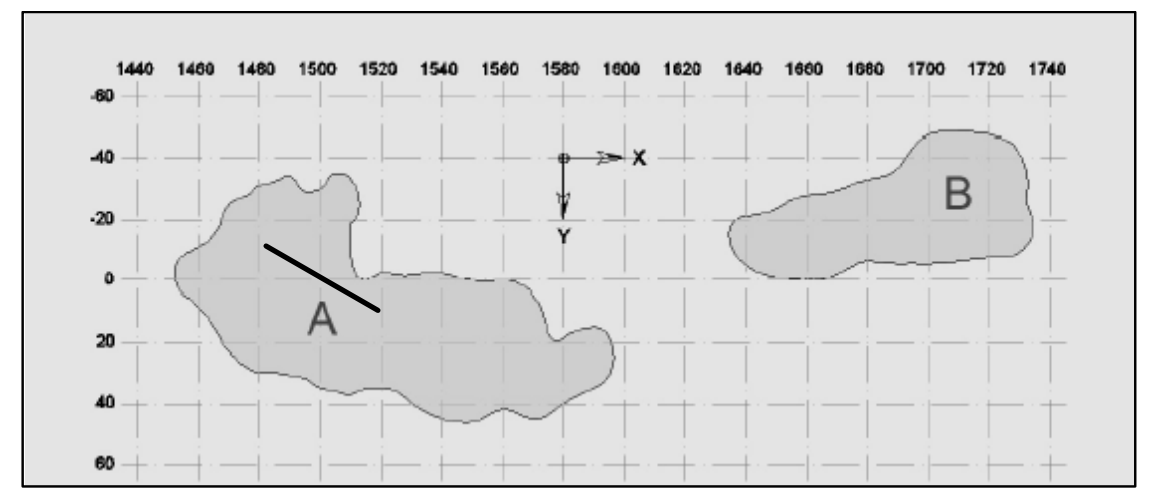

Figure 3: Scour hole planform.

\subsection{Test runs}

Test were carried out for 4 vane heights and 5 vane angles on both the flat bed and the scour bed, leading to a total of $4 \times 5 \times 2=40$ test runs. Table 1 gives an overview of the different experimental settings. 


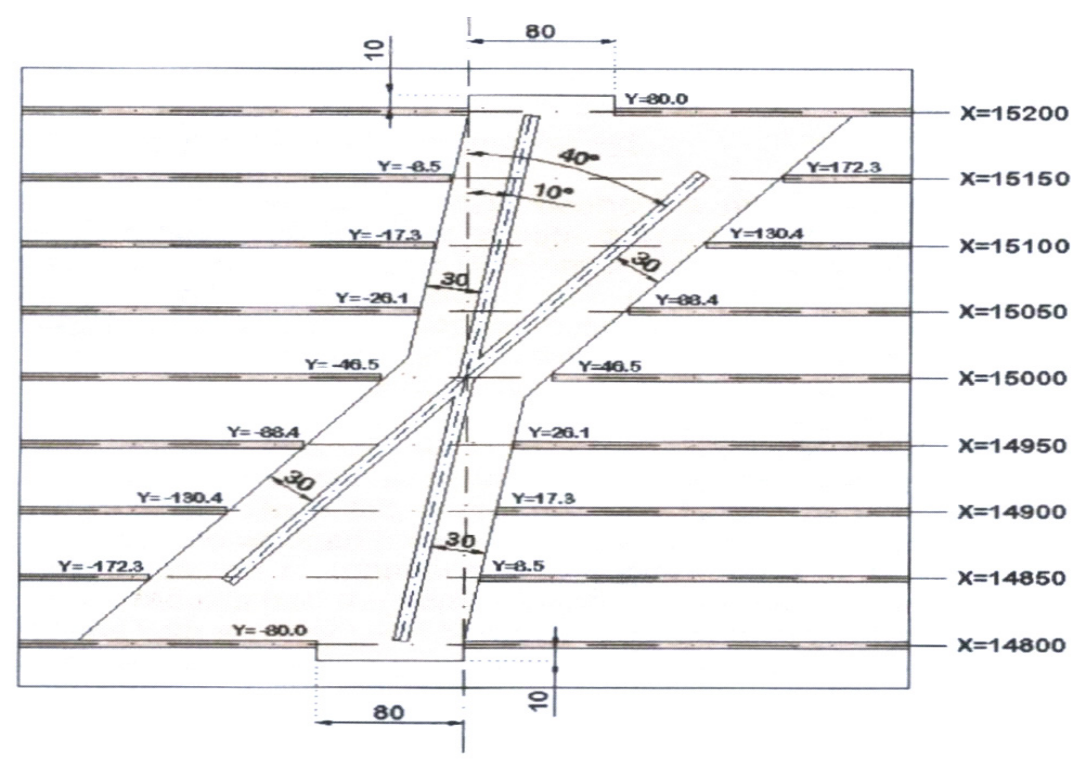

Figure 4: Hourglass-shaped vane gap.

Table 1: Overview of experimental settings.

\begin{tabular}{|c|c|c|}
\hline Vane height $(\mathrm{m})$ & Vane angle $(\mathrm{deg})$ & Bed topography \\
\hline 0.06 & 10 & flat \\
\hline 0.09 & 15 & scour holes \\
\hline 0.12 & 20 & \\
\hline 0.18 & 30 & \\
\hline & 40 & \\
\hline
\end{tabular}

\section{Results and discussion}

The 40 experiments were carried out during a period of 14 months and produced a dataset of 33000 flow velocity vectors for the flat-bed experiments and 36000 flow velocity vectors for the scour-bed experiments, all measured and entered into a computer manually. Figures 5 to 8 present some of the results for different vane heights, $H$, and vane angles, $\alpha$, on the flat bed and the scour bed. They show that a $30^{\circ}$ vane angle yielded the strongest vortex for the $0.18 \mathrm{~m}$ high vane. The vortices generally attenuated by a factor 0.3 to 0.6 over a streamwise distance of 5.7 times the water depth. The presence of scour holes affected the flow, but did not weaken the vortices appreciably. 

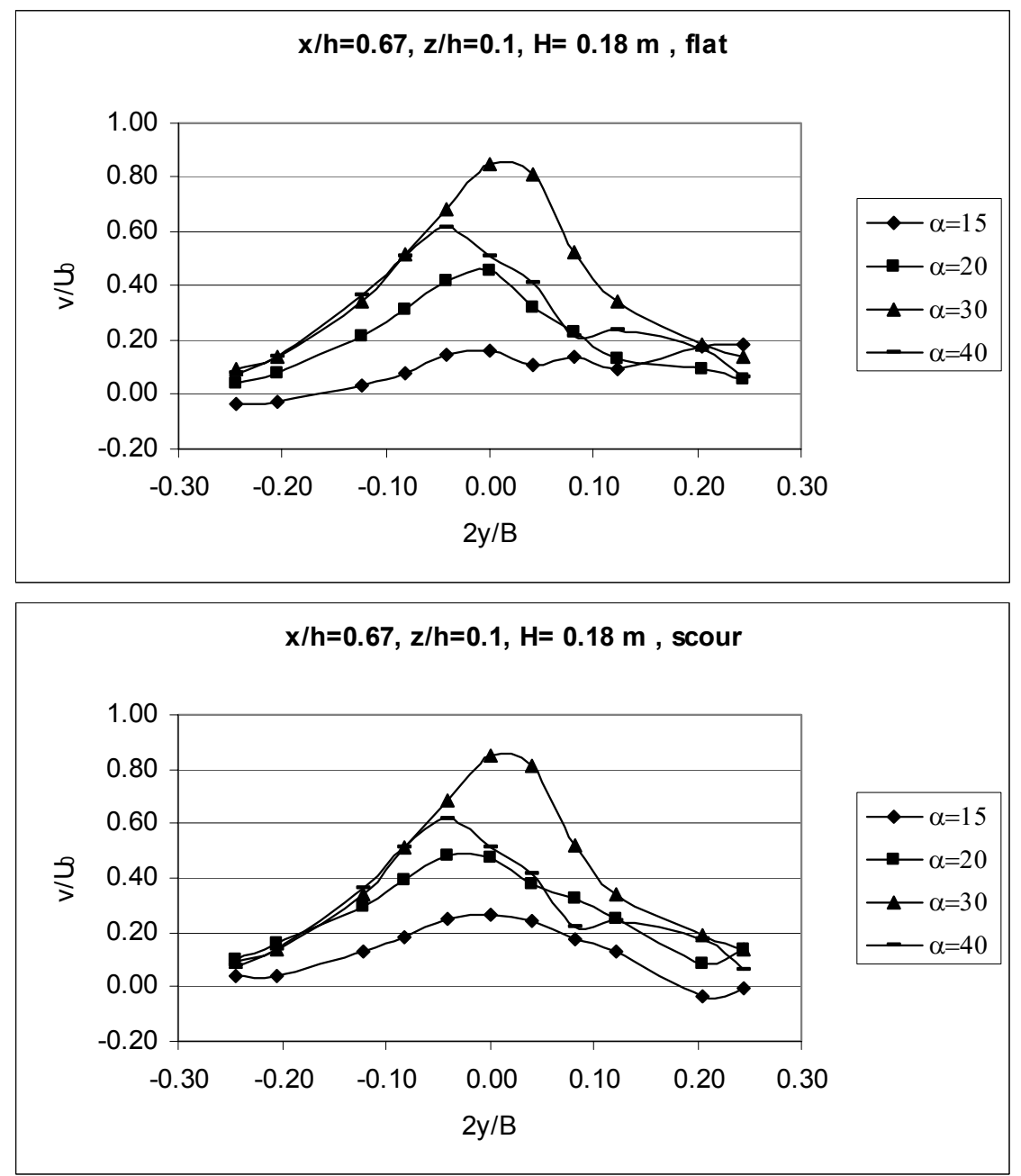

Figure 5: Cross-stream distribution of near-bed cross-stream flow velocity near trailing end of $0.18 \mathrm{~m}$ high vane: flat bed (above) and scour bed (below). 

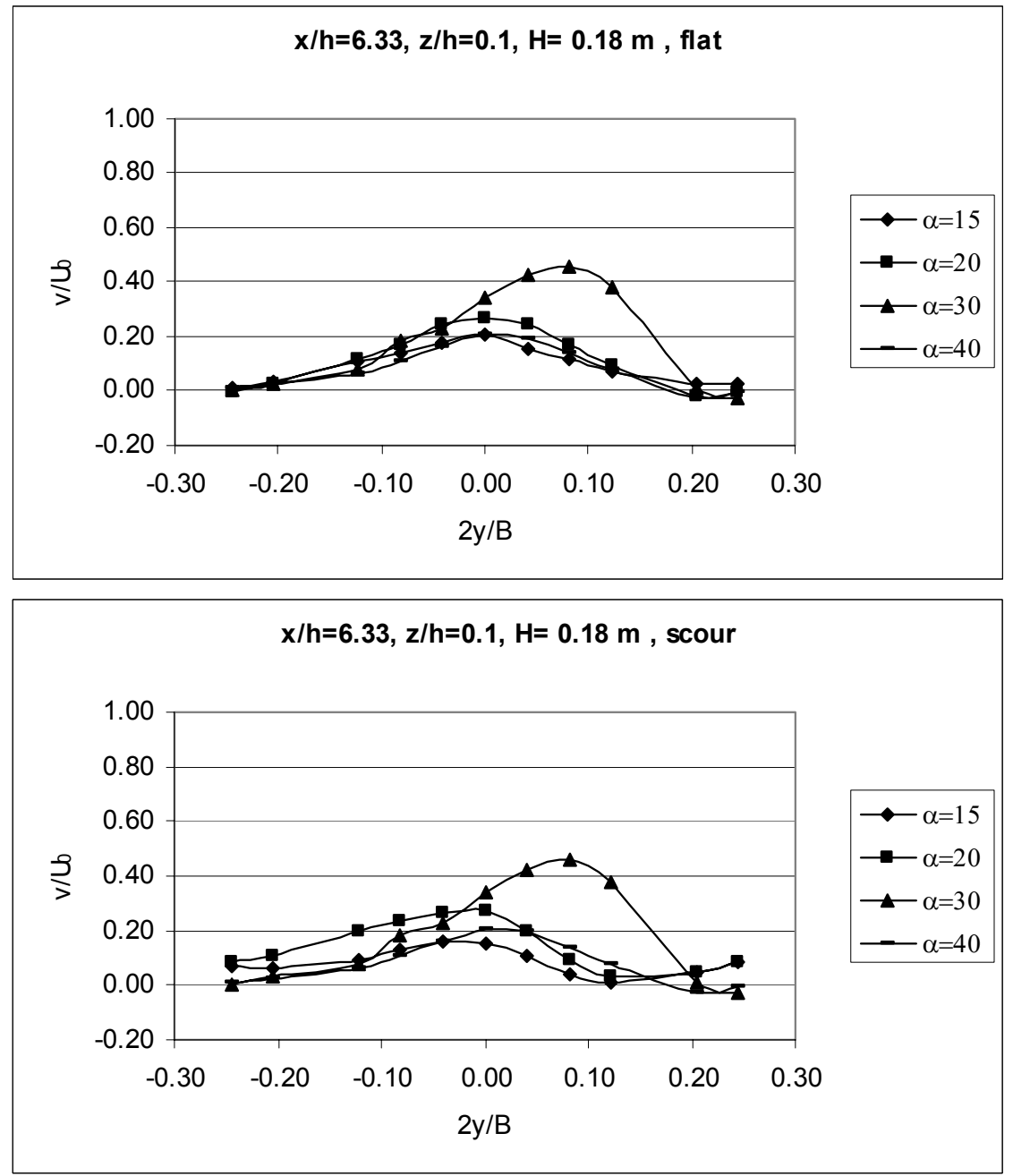

Figure 6: Cross-stream distribution of near-bed cross-stream flow velocity at $6 \mathrm{~m}$ downstream of $0.18 \mathrm{~m}$ high vane: flat bed (above) and scour bed (below). 

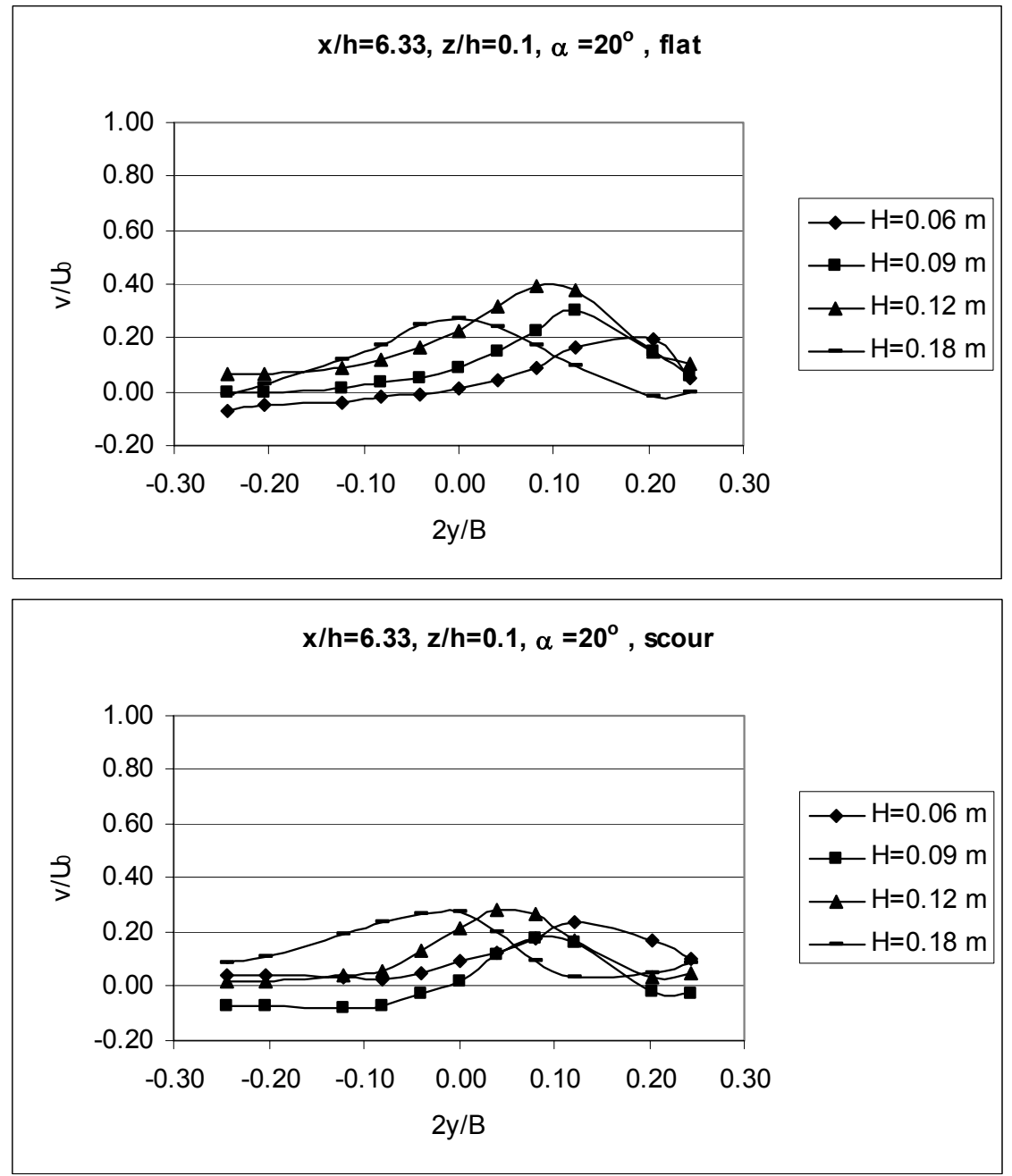

Figure 7: Cross-stream distribution of near-bed cross-stream flow velocity at $6 \mathrm{~m}$ downstream of vane under $20^{\circ}$ to the flow: flat bed (above) and scour bed (below). 

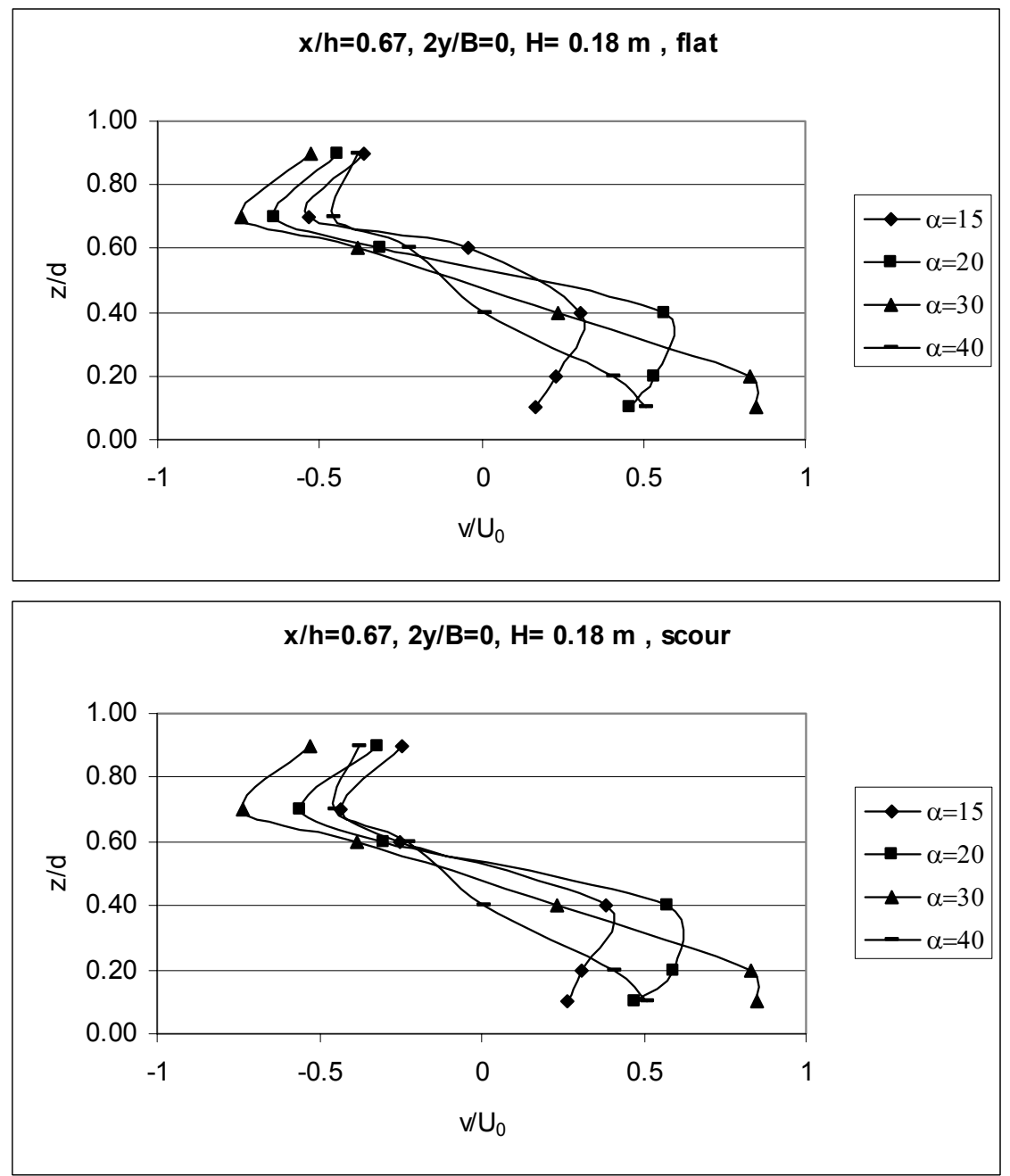

Figure 8: Vertical distribution of cross-stream flow velocity at centre-line near trailing end of $0.18 \mathrm{~m}$ high vane: flat bed (above) and scour bed (below).

\section{Conclusions}

The laboratory tests have produced a rich database that reveals the threedimensional turbulence-averaged flow structure around bottom vanes of different heights and angles, above a flat bed as well as above a bed with two depressions in the shape of natural scour holes. 
The scour holes have been found to affect the flow without appreciably weakening the vane-induced vortices. Hence scour holes are concluded not to jeopardize the effectiveness of bottom vanes for river training purposes.

\section{References}

[1] Potapov, M.V. \& Pyshkin, B.A., Metod poperechnoy tsirkulyatsii i ego primenenie $v$ gidrotekhnike, Izd. Ak. Nayk. SSSR: Moscow and Leningrad, in Russian, 1947.

[2] Remillieux, M., Development of bottom panels in river training. Journal of Waterways, Harbors and Coastal Engineering Division, 98(2), pp.151-162, 1972.

[3] Odgaard, A.J. \& Kennedy, J.F., River-bend bank protection by submerged vanes. Journal of Hydraulic Engineering, 109(8), pp.1161-1173, 1983.

[4] Odgaard, A.J. \& Spoljaric, A., Sediment control by submerged vanes. Journal of Hydraulic Engineering, 112(12), pp.1164-1181, 1986.

[5] Hossain, M.M., Islam, M.R., Saha, S., Ferdousi, S., Van Zwol, B., Zijlstra, R. \& Mosselman, E., Laboratory tests on scour around bottom vanes. Proc. of the $2^{\text {nd }}$ Int. Conf. on Scour and Erosion, eds. Y.-M. Chiew, S.-Y. Lim \& N.-S. Cheng, Stallion Press: Singapore, vol.2, pp.245-251, 2004. 